Check for updates

Cite this: Chem. Sci., 2019, 10, 7003

๑ All publication charges for this article have been paid for by the Royal Society of Chemistry

\title{
Asymmetric Baeyer-Villiger oxidation: classical and parallel kinetic resolution of 3-substituted cyclohexanones and desymmetrization of meso-disubstituted cycloketones $\uparrow$
}

\author{
Wangbin Wu, Weidi Cao, Linfeng Hu, Zhishan Su, (D) Xiaohua Liu (D) * \\ and Xiaoming Feng $\mathbb{D}^{\text {* * }}$
}

Regioselectivity is a crucial issue in Baeyer-Villiger (BV) oxidation. To date, few reports have addressed asymmetric BV oxidation of 3-substituted cycloketones due to the high difficulty of controlling regioand stereoselectivity. Herein, we report the asymmetric BV oxidation of 3-substituted and mesodisubstituted cycloketones with chiral $N, N^{\prime}$-dioxide/Sc(III) catalysts performed in three ways: classical kinetic resolution, parallel kinetic resolution and desymmetrization. The methodology was applied in the total and formal synthesis of bioactive compounds and natural products. Control experiments and calculations demonstrated that flexible and adjustable catalysts played a significant role in the chiral recognition of substrates.

Received 30th March 2019

Accepted 7th June 2019

DOI: $10.1039 / c 9 s c 01563 a$

rsc.li/chemical-science

\section{Introduction}

Asymmetric Baeyer-Villiger oxidation provides direct, efficient access to chiral lactones from cycloketones, ${ }^{1-3}$ including kinetic resolution of racemic cycloketones and desymmetrization of mesomeric cycloketones. Classical kinetic resolution (CKR) and parallel kinetic resolution (PKR) are two main sub-categories in kinetic resolution reactions. Impressive developments have been made in the CKR of highly ring-strained 2-substituted monocyclic ketones and bicyclic cyclobutanones via BV oxidation. ${ }^{4}$ PKR enabled the generation of two regioisomers of lactones. Several examples related to bicyclic cyclobutanones were realized, yet high ee values could not be obtained for both regioisomers simultaneously. ${ }^{5}$ Previously reported desymmetrization of cycloketones via BV oxidation mainly focused on 3substituted cyclobutanones and 4-substituted cyclohexanones. ${ }^{6,7}$ Systematic studies on mesomeric disubstituted cycloketones are scarce; only 3,5-cis-dimethyl cyclohexanone was discussed in biocatalytic cases. ${ }^{7 d f}$ To sum up, despite remarkable advancements in asymmetric BV oxidation, the scope of substrates is still limited. Meanwhile, to develop an efficient catalytic system that can promote all three above-mentioned

Key Laboratory of Green Chemistry and Technology, Ministry of Education, College of Chemistry, Sichuan University, Chengdu 610064, China.E-mail: xmfeng@scu.edu.cn; liuxh@scu.edu.cn

$\dagger$ Electronic supplementary information (ESI) available: ${ }^{1} \mathrm{H},{ }^{13} \mathrm{C},{ }^{19} \mathrm{~F}$ NMR, and HPLC spectra (PDF). X-ray crystallographic data for $\mathbf{5 a}, \mathbf{L}-\mathbf{R a P r}_{2}-\mathbf{t} \mathbf{B u} / \mathrm{Sc}(\mathrm{OTf})_{3}$ (CIF). CCDC 1848335 and 1856535. For ESI and crystallographic data in CIF or other electronic format see DOI: 10.1039/c9sc01563a types of Baeyer-Villiger oxidation reactions is also highly meaningful. ${ }^{4 b, 6 b, 7 e}$

On the other hand, regioselectivity has long been a "camphor mystery" in BV oxidation. ${ }^{2 c, 8}$ In comparison with 2-substituted cyclic ketones, asymmetric BV oxidation of 3-substituted cyclic ketones (cyclopentanones and cyclohexanones) was less discussed owing to the high difficulty to control regio- and stereoselectivity. ${ }^{9}$ Several biocatalyst-promoted reactions have been reported with moderate stereoselectivity ${ }^{9 c}$ or regioselectivity. ${ }^{9 a, b, d}$ In 2014, Miller's group developed the asymmetric BV

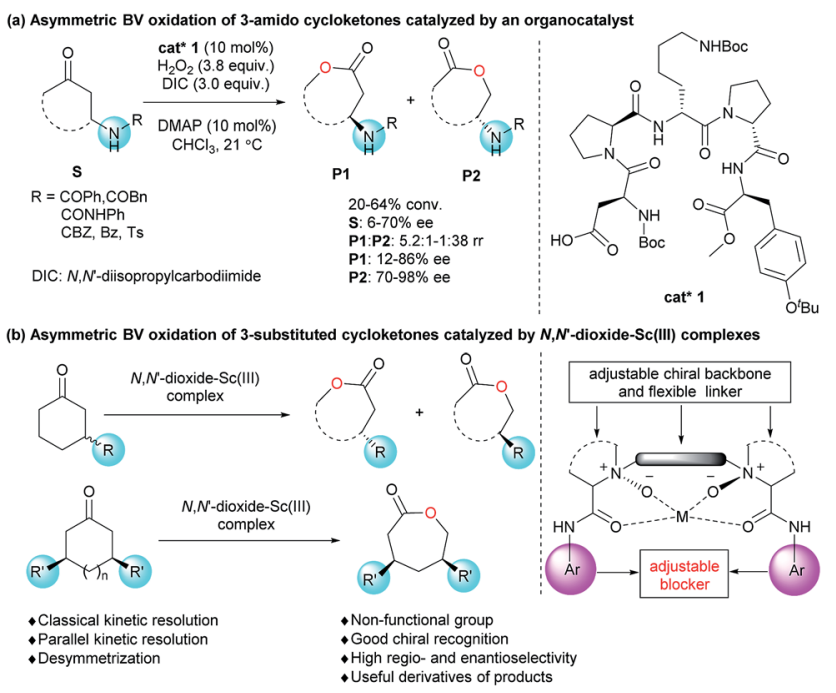

Scheme 1 Asymmetric Baeyer-Villiger oxidation of 3-substituted cycloketones. 
oxidation of 3-substituted cycloketones with a peptide-based organocatalyst, where hydrogen bonding between the catalyst and the functional groups of the substrates resulted in moderate to good regio- and stereoselectivities (Scheme 1a). ${ }^{9 f}$

The induced-fit model of BV oxidation in biocatalysis provides such a sight of view for molecular catalysts that a conformationally flexible structure can streamline the adjustment of catalysts toward cycloketones with different configurations and conformations, leading to high regio- and stereo-selectivity. ${ }^{\boldsymbol{4} \boldsymbol{d}, \boldsymbol{4 f}, \boldsymbol{t c}, \mathbf{1 0}}$ The privileged chiral $N, N^{\prime}$-dioxide, bearing a catenulate alkyl linker as well as two backbones and aniline groups bound to Lewis acids, is by nature a flexible structure, ${ }^{\mathbf{1 1}}$ which forms an adjustable blocker for chiral recognition. Herein, we describe novel CKR, PKR and desymmetrization of 3-substituted cycloketones (non-functional group) with a single chiral $N, N^{\prime}$-dioxide/Sc(III) catalytic system (Scheme 1b).

\section{Results and discussion}

Our investigation began with the CKR of racemic 3-phenyl cyclohexanone (1a) by using $m$-chloro peroxobenzoic acid $(\mathrm{m}$ CPBA, 0.5 equiv.) as an oxidant in the presence of $5 \mathrm{~mol} \% \mathrm{~L}$ $\mathbf{P r P r}_{2} / \mathrm{Sc}(\mathrm{OTf})_{3}$ complex in EtOAc at $30{ }^{\circ} \mathrm{C}$ (Table 1, entry 1). The corresponding mixture of lactones $\mathbf{2 a}$ and $\mathbf{3 a}$ was obtained in moderate yield with poor regio- and stereoselectivity, while racemic 1a was recovered. Next, the backbones of the chiral $N, N^{\prime}$-dioxide ligands were evaluated and found to have an important effect on the regio- and stereoselectivity (Fig. 1). L$\mathbf{R a P r}_{2}$ derived from L-ramipril was superior to L-proline-derived $\mathbf{L}-\mathbf{P r P r}_{2}$ and L-pipecolic acid derived L-PiPr 2 (Table 1, entry $3 v s$. 1-2). Both regio- and stereoselectivity of the reaction were improved by introducing a bulky group into the para-position of the phenyl group in the ligand (Table 1, entries 4 and 5). For

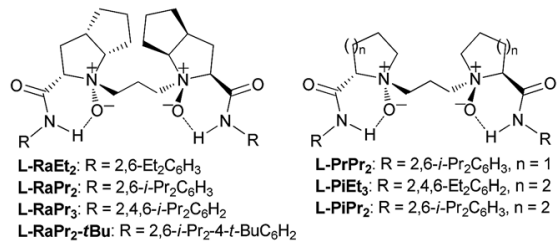

Fig. 1 Chiral $N, N^{\prime}$-dioxide ligands used in this work.

instance, the ligand $\mathbf{L}-\mathbf{R a P r}_{\mathbf{2}}-\mathbf{t} \mathbf{B u}$ bearing tert-butyl groups, coordinated with $\mathrm{Sc}(\mathrm{OTf})_{3}$, catalyzed the reaction and gave a mixture of $2 \mathbf{a}$ and $3 \mathbf{a}$ in an $83: 17$ ratio with $81 \%$ ee of $2 \mathbf{a}$ (Table 1 , entry 5). Upon lowering the temperature to $0{ }^{\circ} \mathrm{C}$, the ratio of $2 \mathrm{a}$ to $3 \mathrm{a}$ could be improved to $85: 15$ and the ee value of 2a was increased to $85 \%$ in $12 \mathrm{~h}$ (Table 1 , entry 6). However, upon further decreasing the temperature to $-20{ }^{\circ} \mathrm{C}$, no better result was achieved (Table 1 , entry 7 ). To our delight, the regioand stereoselectivity had a significant improvement with the addition of $\mathrm{Al}(\mathrm{Oi}-\mathrm{Pr})_{3}{ }^{4,6 f}(\mathbf{2 a}: \mathbf{3 a}=91: 9,93 \%$ ee of $\mathbf{2 a}$, and $81 \%$ ee of recovered 1a), albeit with prolonged reaction time $(72 \mathrm{~h})$ (Table 1, entry 8). It was found that when $\mathrm{Al}(\mathrm{Oi}-\mathrm{Pr})_{3}$ and $3 \AA$ MS were both used as additives, optimal reaction results could be obtained within $48 \mathrm{~h}$ (Table 1, entry $9,48 \%$ yield of the mixture of $2 \mathbf{a}$ and $3 \mathbf{a}, \mathbf{2 a}: 3 \mathbf{a}=92: 8,93 \%$ ee of $\mathbf{2 a}, 48 \%$ yield of $\mathbf{1 a}$, and $82 \%$ ee of $1 \mathrm{a})$.

The substrate scope of CKR was then explored. A range of racemic 3-aryl cyclohexanones were transformed into the corresponding lactones smoothly under the optimized reaction conditions. Regardless of the presence of electron donating or withdrawing groups on the 3-phenyl group, excellent yields and moderate to good regioselectivities with good ee values of $\mathbf{2 a}-\mathbf{2} \mathbf{g}$ were obtained (Table 2, entries 1-7, 45-49\% yields, 85-93\% ee of 2 , and up to $95: 5 \mathrm{rr}$ ). For the condensed-ring substrate $\mathbf{1 h}$

Table 1 Condition optimization for the CKR of racemic 3-phenyl cyclohexanones

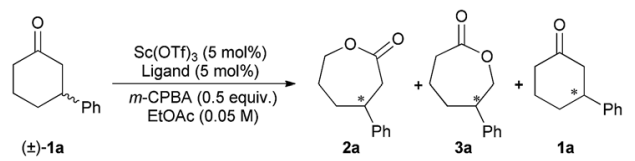

\begin{tabular}{|c|c|c|c|c|c|c|c|c|c|}
\hline Entry $^{a}$ & Ligand & $T\left({ }^{\circ} \mathrm{C}\right)$ & Additives & \multicolumn{3}{|c|}{ Yield $^{b}(\%)$} & \multicolumn{3}{|c|}{$\mathrm{ee}^{c}(\%)$} \\
\hline 2 & L-PiPr 2 & 30 & - & 49 & 50 & $51: 49$ & 2 & 23 & 17 \\
\hline 3 & L-RaPr 2 & 30 & - & 47 & 43 & $75: 25$ & 13 & 69 & 84 \\
\hline 4 & $\mathbf{L}-\mathrm{RaPr}_{3}$ & 30 & - & 49 & 51 & $82: 18$ & 42 & 77 & 72 \\
\hline $7^{e}$ & $\mathrm{~L}-\mathrm{RaPr}_{2}-t \mathrm{Bu}$ & -20 & - & 73 & 25 & $89: 11$ & 24 & 73 & 89 \\
\hline $8^{e f}$ & $\mathrm{~L}-\mathrm{RaPr}_{2}-t \mathrm{Bu}$ & -20 & $\mathrm{Al}(\mathrm{Oi}-\mathrm{Pr})_{3}$ & 49 & 50 & $91: 9$ & 81 & 93 & 96 \\
\hline $9^{g}$ & $\mathrm{~L}-\mathrm{RaPr}_{2}-t \mathrm{Bu}$ & -20 & $3 \AA \mathrm{MS}$ & 48 & 48 & $92: 8$ & 82 & 93 & 91 \\
\hline
\end{tabular}

${ }^{a}$ Unless otherwise specified, the reaction was performed with Sc(OTf) $)_{3}(5 \mathrm{~mol} \%)$, ligand ( $\left.5 \mathrm{~mol} \%\right), 1 \mathrm{a}(0.20 \mathrm{mmol})$ and $m$-CPBA (0.5 equiv.) in EtOAc $(0.05 \mathrm{M})$ at $30^{\circ} \mathrm{C}$ for $12 \mathrm{~h}$ under an air atmosphere. ${ }^{b}$ Yields of the isolated products. ${ }^{c}$ Determined by HPLC analysis using a chiral stationary phase.

${ }^{d}$ At $0{ }^{\circ} \mathrm{C} .{ }^{e}$ At $-20{ }^{\circ} \mathrm{C}$ for $72 \mathrm{~h} .^{f} \mathrm{Al}(\mathrm{Oi}-\mathrm{Pr})_{3}(50 \mathrm{~mol} \%)$ was added. ${ }^{g}$ At $-20{ }^{\circ} \mathrm{C}$ for $48 \mathrm{~h}, \mathrm{Al}(\mathrm{Oi}-\mathrm{Pr})_{3}(50 \mathrm{~mol} \%)$ and $3 \AA \mathrm{AS}(50 \mathrm{mg})$ were added. 
Table 2 Substrate scope for the CKR of racemic 3-substituted cyclohexanones

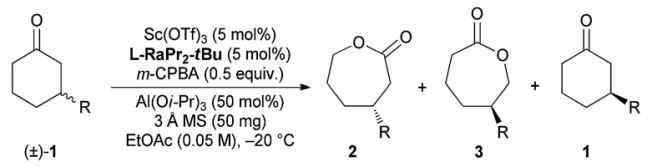

\begin{tabular}{|c|c|c|c|c|c|c|c|}
\hline \multirow[b]{2}{*}{ Entry $^{a}$} & \multirow[b]{2}{*}{$\mathrm{R}$} & \multicolumn{3}{|c|}{ Yield $^{b}(\%)$} & \multicolumn{3}{|c|}{$\mathrm{ee}^{c}\left({ }^{\mathrm{b}}\right)$} \\
\hline & & 1 & $2+3$ & $2: 3^{c}$ & 1 & 2 & 3 \\
\hline 1 & $\mathrm{Ph}(\mathbf{1 a})$ & 48 & 48 & $92: 8$ & 82 & 93 & 9 \\
\hline 2 & $2-\mathrm{MeC}_{6} \mathrm{H}_{4}(\mathbf{1 b})$ & 48 & 48 & $90: 10$ & 72 & 88 & 73 \\
\hline 3 & $3-\mathrm{MeC}_{6} \mathrm{H}_{4}(\mathbf{1 c})$ & 46 & 49 & $82: 18$ & 67 & 91 & 61 \\
\hline 4 & $4-\mathrm{MeC}_{6} \mathrm{H}_{4}(\mathbf{1 d})$ & 49 & 47 & $88: 12$ & 67 & 85 & 90 \\
\hline 5 & $4-n-\mathrm{BuC}_{6} \mathrm{H}_{4}(\mathbf{1 e})$ & 42 & 45 & $88: 12$ & 79 & 90 & 96 \\
\hline 6 & $3-\mathrm{ClC}_{6} \mathrm{H}_{4}(\mathbf{1 f})$ & 49 & 49 & $90: 10$ & 74 & 90 & 75 \\
\hline 7 & $4-\mathrm{F}_{3} \mathrm{CC}_{6} \mathrm{H}_{4}(1 \mathrm{~g})$ & 43 & 45 & $95: 5$ & 88 & 91 & 73 \\
\hline 8 & 2-Naphthyl (1h) & 49 & 50 & $95: 5$ & 62 & 87 & 98 \\
\hline 9 & Bn (1i) & 43 & 48 & $70: 30$ & 40 & 82 & 97 \\
\hline 10 & $\operatorname{Me}(\mathbf{1} \mathbf{j})$ & 43 & 44 & $74: 26$ & 55 & 90 & 95 \\
\hline
\end{tabular}

${ }^{a}$ Unless otherwise specified, the reaction was performed with $\mathrm{Sc}(\mathrm{OTf})_{3}$ (5 mol\%), L-RaPr ${ }_{2}-t$ Bu ( 5 mol\%), $\mathbf{1 a}(0.20 \mathrm{mmol}), m$-CPBA ( 0.5 equiv.), $\mathrm{Al}(\mathrm{Oi}-\mathrm{Pr})_{3}(50 \mathrm{~mol} \%)$ and $3 \AA \mathrm{MS}(50 \mathrm{mg})$ in EtOAc $(0.05 \mathrm{M})$ under an air atmosphere. ${ }^{b}$ Yields of the isolated products. ${ }^{c}$ Determined by HPLC or SFC analysis using a chiral stationary phase. For the absolute configuration of the products, see the ESI for more details.

(Table 2, entry 8), the desired products were obtained in $50 \%$ yield and $87 \%$ ee of $2 \mathbf{h}$ with $95: 5$ rr. 3-Alkyl substituted cyclohexanones $\mathbf{1 i}(\mathrm{Bn})$ and $\mathbf{1 j}(\mathrm{Me})$ were also tolerated in this catalytic system, providing the corresponding lactones in $48 \%$ yield, $82 \%$ ee of $2 \mathbf{i}$ with $70: 30 \mathrm{rr}$ and $44 \%$ yield, and $90 \%$ ee of $2 \mathbf{j}$ with $74: 26 \mathrm{rr}$, respectively (Table 2, entries 9 and 10). The ee values of the minor isomers $3 \mathbf{i}$ and $3 \mathbf{j}$ were excellent (97\% ee and $95 \%$ ee). All the unreacted 3-aryl cyclohexanones 1 were recovered in excellent yields with moderate to good ee values.

Then, we turned our attention to the PKR of racemic 3substituted cyclohexanones. After a slight modification of the reaction conditions (see Table S1 in the ESI for details $\dagger$ ), by altering the ligand $\mathbf{L}-\mathbf{R a P r}_{2}-\mathbf{t} \mathbf{B u}$ to $\mathbf{L}-\mathbf{R a E t}_{\mathbf{2}}$ as well as increasing the catalyst loading to $10 \mathrm{~mol} \%$ and the reaction concentration to $0.10 \mathrm{M}, 2 \mathrm{a}$ and $3 \mathrm{a}$ were obtained with $81 \%$ ee and $97 \%$ ee (Table 3, entry 1). The PKR of other 3-aryl substituted cyclohexanones proceeded well to give both lactone isomers with good to excellent enantioselectivities (Table 3, entries 2-7, 80$83 \%$ ee of 2 and $91-97 \%$ ee of 3 ). Substrate 11 bearing a $n$-butyl group was converted into the desired oxidation products in $84 \%$ mixed yield and 62 : $38 \mathrm{rr}$ with $87 \%$ ee of $\mathbf{2 l}$ and $97 \%$ ee of $3 \mathbf{1}$.

Inspired by the CKR and PKR of 3-substituted cyclohexanones, we then focused on the desymmetrization of cis-3,5diphenyl cyclohexanones. Upon further survey of the reaction parameters, the optimal conditions were found to be $\mathbf{4}(0.10$ mmol), $m$-CPBA $(0.10 \mathrm{mmol}), \mathbf{L}-\mathrm{RaPr}_{2} / \mathrm{Sc}(\mathrm{OTf})_{3}$ complex $(1: 1$, $10 \mathrm{~mol} \%$ ) and $3 \AA \mathrm{MS}(50 \mathrm{mg})$ in EtOAc at $0^{\circ} \mathrm{C}$ for $48 \mathrm{~h}$ (see Table $\mathrm{S} 4$ in the ESI for details $\dagger$ ). The substituents on the phenyl group of the cyclohexanones were proven to have little effect on this reaction, and a series of desymmetrization products $\mathbf{5 a}-\mathbf{5} \mathbf{g}$ were
Table 3 Substrate scope for the PKR of racemic 3-substituted cyclohexanones

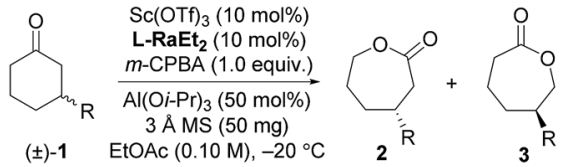

\begin{tabular}{|c|c|c|c|c|c|}
\hline \multirow[b]{2}{*}{ Entry $^{a}$} & \multirow[b]{2}{*}{$\mathrm{R}$} & \multicolumn{2}{|c|}{ Yield $^{b}(\%)$} & \multicolumn{2}{|c|}{$\mathrm{ee}^{c}(\%)$} \\
\hline & & $2+3$ & $2: 3^{c}$ & 2 & 3 \\
\hline 1 & $\mathrm{Ph}(\mathbf{1 a})$ & 98 & $55: 45$ & 81 & 97 \\
\hline 2 & $2-\mathrm{MeC}_{6} \mathrm{H}_{4}(\mathbf{1 b})$ & 94 & $56: 44$ & 80 & 93 \\
\hline 3 & $3-\mathrm{MeC}_{6} \mathrm{H}_{4}(\mathbf{1 c})$ & 97 & $53: 47$ & 82 & 91 \\
\hline 4 & $4-\mathrm{MeC}_{6} \mathrm{H}_{4}(\mathbf{1 d})$ & 97 & $55: 45$ & 80 & 96 \\
\hline 5 & $4-n-\mathrm{BuC}_{6} \mathrm{H}_{4}(\mathbf{1 e})$ & 98 & $55: 45$ & 83 & 95 \\
\hline 6 & $4-\mathrm{MeOC}_{6} \mathrm{H}_{4}(\mathbf{1 k})$ & 92 & $52: 48$ & 83 & 97 \\
\hline 7 & 2-Naphthyl (1h) & 94 & $55: 45$ & 81 & 96 \\
\hline 8 & $n$-Bu (1l) & 84 & $62: 38$ & 87 & 97 \\
\hline \multicolumn{6}{|c|}{$\begin{array}{l}\left.{ }^{a} \text { Unless otherwise specified, the reaction was performed with Sc(OTf }\right)_{3} \\
(10 \mathrm{~mol} \%), \mathbf{L}-\mathrm{RaEt}_{2}(10 \mathrm{~mol} \%), \mathbf{1}(0.10 \mathrm{mmol}), \mathrm{m} \text {-CPBA }(1.0 \text { equiv.), } \\
\mathrm{Al}(\mathrm{Oi}-\mathrm{Pr})_{3}(50 \mathrm{~mol} \%) \text { and } 3 \AA \mathrm{MS}(50 \mathrm{mg}) \text { in EtOAc }(0.10 \mathrm{M}) \text { at }-20{ }^{\circ} \mathrm{C} \\
\text { under an air atmosphere. }{ }^{b} \text { Yields of the isolated products. } \\
{ }^{c} \text { Determined by HPLC or SFC analysis using a chiral stationary phase. } \\
\text { For the absolute configuration of the products, see the ESI for more } \\
\text { details. }\end{array}$} \\
\hline
\end{tabular}

obtained in excellent yields and enantioselectivities (Table 4, entries 1-7, 96-99\% yields, and $93-97 \%$ ee). The absolute configuration of $\mathbf{5 a}$ was determined to be $(4 R, 6 R)$ by X-ray crystallographic analysis. ${ }^{12 a}$ Dimethyl substituted $\mathbf{4 h}$ could

Table 4 Substrate scope for the desymmetrization of meso-disubstituted cycloketones

\begin{tabular}{|c|c|c|c|}
\hline & $\prod_{\substack{4 a-4 h, n=1 \\
4 i, n=0}}^{0}$ & $\sum_{\substack{5 a-5 n, n=1 \\
5 i, n=0}}^{O N}$ & \\
\hline Entry $^{a}$ & $\mathrm{R}$ & Yield $^{b}(\%)$ & $\mathrm{ee}^{c}(\%)$ \\
\hline 1 & $\mathrm{Ph}(\mathbf{4 a})$ & 97 & 96 \\
\hline 2 & $3-\mathrm{MeC}_{6} \mathrm{H}_{4}(\mathbf{4 b})$ & 98 & 97 \\
\hline 3 & $4-\mathrm{OMeC}_{6} \mathrm{H}_{4}(4 \mathrm{c})$ & 96 & 93 \\
\hline 4 & $4-\mathrm{FC}_{6} \mathrm{H}_{4}(\mathbf{4 d})$ & 98 & 94 \\
\hline 5 & $3-\mathrm{ClC}_{6} \mathrm{H}_{4}(4 \mathbf{e})$ & 99 & 93 \\
\hline 6 & $4-\mathrm{ClC}_{6} \mathrm{H}_{4}(\mathbf{4 f})$ & 98 & 94 \\
\hline 7 & $4-\mathrm{BrC}_{6} \mathrm{H}_{4}(4 \mathrm{~g})$ & 99 & 94 \\
\hline 8 & $\mathrm{Me}(4 \mathbf{h})$ & 99 & 91 \\
\hline $9^{d}$ & $\mathrm{Ph}(4 \mathbf{i})$ & 99 & 96 \\
\hline
\end{tabular}

${ }^{a}$ Unless otherwise specified, the reaction was performed with $\mathrm{Sc}(\mathrm{OTf})_{3}$ (10 mol\%), L-RaPr 2 (10 mol\%), 4 ( $0.10 \mathrm{mmol}), m$-CPBA (1.0 equiv.), and 4 $\AA \mathrm{MS}(50 \mathrm{mg})$ in EtOAc $(0.05 \mathrm{M})$ at $-20{ }^{\circ} \mathrm{C}$ for $48 \mathrm{~h}$ under an air atmosphere. ${ }^{b}$ Yields of the isolated products. ${ }^{c}$ Determined by HPLC or SFC analysis using a chiral stationary phase. For the absolute configuration of the products, see the ESI for more details. ${ }^{d}$ For $4 \mathbf{i}, n$ $=0 ; \mathbf{L}^{-\mathbf{P i E t}_{3}}$ was used instead of $\mathbf{L}-\mathbf{R a P r}_{2}$ at $0{ }^{\circ} \mathrm{C}$ for $24 \mathrm{~h}$. 
undergo transformation as well and gave the target lactone $\mathbf{5 h}$ in $99 \%$ yield with $91 \%$ ee (Table 4 , entry 8 ). In addition, 3,4-diphenyl cyclopentanone $4 \mathbf{i}$ was also tolerated in this desymmetrization reaction (Table 4, entry 9, 99\% yield, 96\% ee).

$(S)$-C4-benzyl suberoylanilide hydroxamic acid (SAHA) exhibits high selectivity for histone deacetylases (HDAC) 6 and 8 , which can regulate gene expression via deacetylation of nucleosomal histones. Recently, Pflum's group realized the synthesis of the $(S)$-C4-benzyl SAHA analog in 9 steps $(6.3 \%$ overall yield) from $(R)$-4-benzyloxazolidin-2-one. ${ }^{13}$ In contrast, as shown in Scheme 2a, the $(S)$-C4-benzyl SAHA analog could be obtained in $31 \%$ overall yield with $94 \%$ ee in 6 steps from racemic 1i, involving the key step of asymmetric BV oxidation of $1 \mathbf{i}$ to a mixture of $2 \mathbf{i}$ and $3 \mathbf{i}$. The $S y n$-1,3-dimethyl moiety served as a core chiral skeleton in various natural products, ${ }^{\mathbf{1 4}}$ such as mycolipenic acid, mycolipanolic acid and (-)-rasfonin. Manipulating the desymmetrization product $\mathbf{5 h}$ with a two-step transformation, syn-1,3-dimethyl thioester 10 was obtained, which could be easily transformed into the
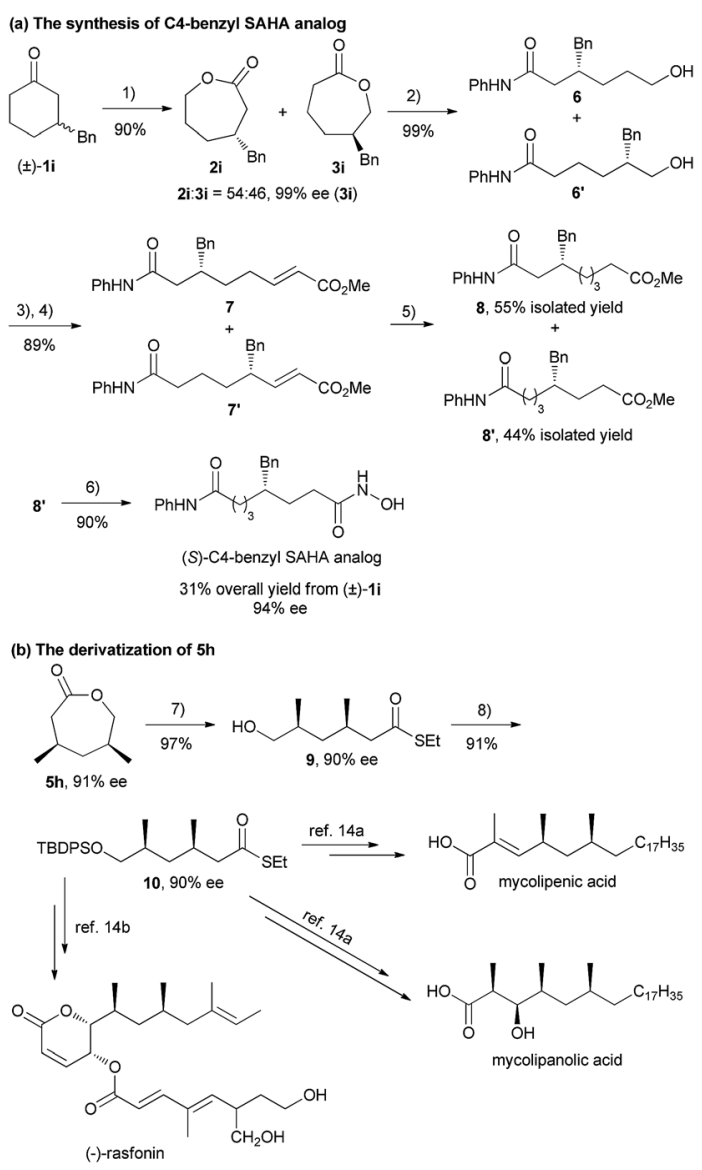

Scheme 2 The synthesis of the (S)-C4-benzyl SAHA analog and the derivatization of $5 \mathrm{~h}$. (1) $m$-CPBA (1.0 equiv.), L- $\operatorname{RaPr}_{2}-t \mathrm{Bu} / \mathrm{Sc}(\mathrm{OTf})_{3}$ (1 : $1,10 \mathrm{~mol} \%), \mathrm{Al}(\mathrm{Oi}-\mathrm{Pr})_{3}(50 \mathrm{~mol} \%), 3 \AA \mathrm{MS}(50 \mathrm{mg}), \mathrm{EtOAc}(0.05 \mathrm{M})$, $-20{ }^{\circ} \mathrm{C}$ for 48 h. (2) $\mathrm{PhNH}_{2}$ (2.0 equiv.), $\mathrm{AlMe}_{3}$ (2.0 equiv.), $\mathrm{THF}, 0^{\circ} \mathrm{C}$ to rt. (3) PCC (2.0 equiv.), celite, $\mathrm{N}_{2}$, DCM. (4) $(\mathrm{OMe})_{2}(\mathrm{O}) \mathrm{PCH}_{2} \mathrm{COOMe} \mathrm{(1.4}$ equiv.), $\mathrm{NaH}$ (1.5 equiv.), THF. (5) $\mathrm{Pd} / \mathrm{C}, \mathrm{H}_{2}, \mathrm{MeOH}$. (6) $\mathrm{H}_{2} \mathrm{NOH} \cdot \mathrm{HCl}$, $\mathrm{KOH}, \mathrm{MeOH}, 0{ }^{\circ} \mathrm{C}$. (7) EtSH, $\mathrm{AlMe}_{3}, \mathrm{THF}, 0{ }^{\circ} \mathrm{C}$ to rt. (8) TBDPSCl, $\mathrm{NaH}$, EtOAc. aforementioned natural products (Scheme 2b, see the ESI for details $\dagger$ ).

To elucidate the regioselectivity in both CKR and PKR, several control experiments were conducted. First, when $\mathrm{Sc}(\mathrm{OTf})_{3}$ was used to promote the CKR of 1a without a ligand, only $21 \%$ mixed yield of $2 \mathrm{a}$ and $3 \mathrm{a}$ with $50: 50 \mathrm{rr}$ was obtained (Scheme 3a). Furthermore, when the enantiopure substrate $(S)$ 1a was tested under the standard conditions of CKR type of BV oxidation with the ligand $e n t-\mathbf{L}-\mathbf{R a P r}_{2}-\mathbf{t B u}$ derived from $\mathrm{D}$ ramipril, a mixture of $\mathbf{2 a}$ and $\mathbf{3 a}$ was obtained in quantitative yield. However, when $\mathbf{L}-\mathbf{R a P r}_{2}-\mathbf{t} \mathbf{B u}$ was used, the reactivity was diminished and lower regioselectivity was obtained (Scheme $3 \mathrm{~b})$. These results suggest that $(S) \mathbf{- 1 a}$ matched with ent-L-RaPr $\mathbf{2}^{-}$ $\boldsymbol{t} \mathbf{B u}$ and gave the major product $(S)$-2a; however, $(S)$-1a mismatched with $\mathbf{L}-\mathbf{R a P r}_{\mathbf{2}}-\mathbf{t} \mathbf{B u}$ and revealed poorer reactivity to give $(R)$-3a. A similar phenomenon was also observed in the PKR type of BV oxidation with $\mathbf{L}-\mathbf{R a E t}_{\mathbf{2}}$ and ent-L-RaEt $\mathbf{2}_{\mathbf{2}}$ as the ligands (Scheme 3c).

As discussed above, the migratory aptitude of 1a contributed little to the regioselectivity in the formation of lactones (Scheme 3a). We proposed that the stereoelectronic effect in the Criegee intermediate, a notion that the migrating group needs to be antiperiplanar to the leaving group in peroxide acids before the migration of the alkyl group in the Criegee intermediate, could be essential for the recognition of 1a (Fig. 2a). ${ }^{3 d, e}$ Since different aniline groups in $\mathbf{L}-\mathbf{R a P r}_{\mathbf{2}}-\mathbf{t} \mathbf{B u} \mathbf{u}^{\mathbf{1 2 b}}$ and $\mathbf{L}-\mathbf{R a E t}_{\mathbf{2}}$ resulted in different steric hindrances between 1a and catalysts, the energy difference in the alkyl migration step in the formation of $2 \mathbf{a}$ and 3a with different configurations would result in the difference of regioselectivity. To provide further evidence for the above conjecture, ONIOM (M06/6-31G*: HF/STO-3G) calculations were performed (see the ESI for details $\dagger$ ). Based on previous theoretical studies of $\mathrm{BV}$ oxidation with chiral $N, N^{\prime}$-dioxide/Sc(III) catalysts, ${ }^{15}$ the transition states in the alkyl group migration step in CKR and PKR were optimized and their Gibbs free energies were calculated (Fig. 2b, c). In L-RaPr $\mathbf{~}_{\mathbf{2}}-\mathbf{t B u}-\mathrm{TS}-(R)-\mathbf{2 a}$ and $\mathbf{L}-\mathbf{R a E t}_{\mathbf{2}}$-TS- $(R)-\mathbf{2 a}$, 1a was placed away from the aniline groups, while in $\mathbf{L}-\mathbf{R a P r}_{\mathbf{2}}-\mathbf{t} \mathbf{B u}-\mathrm{TS}-(R)-\mathbf{3 a}$ and $\mathbf{L}-\mathbf{R a E t}_{\mathbf{2}}$-TS- $(R)-\mathbf{3 a} \mathbf{a} \mathbf{1 a}$ was placed between the aniline group and the bicyclic ring

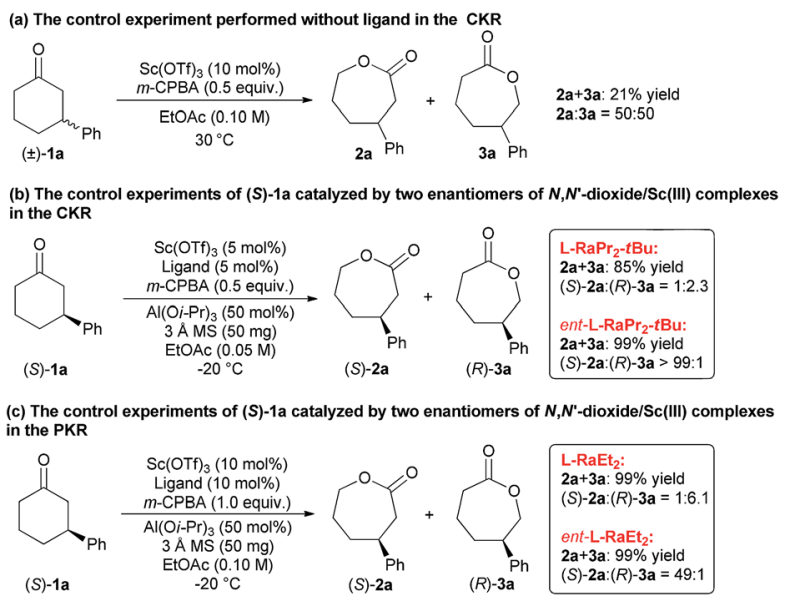

Scheme 3 Control experiments. 


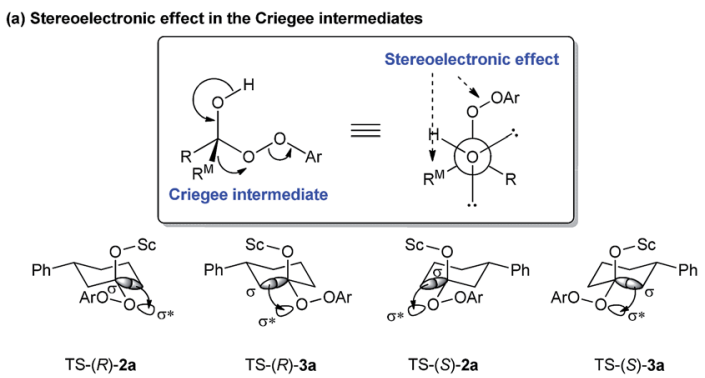

(b) Gibbs free energy of transition states in CKR via BV oxidation
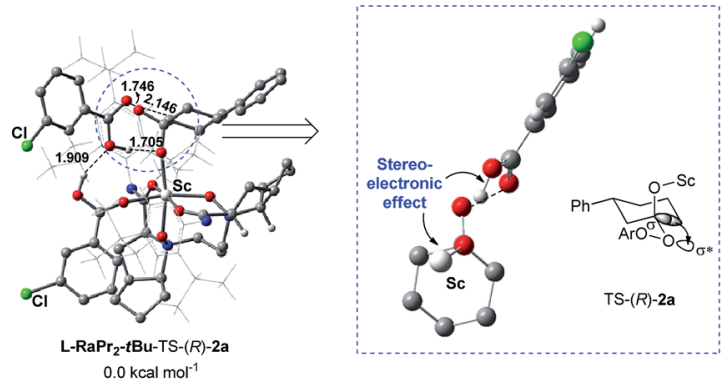

$0.0 \mathrm{kcal} \mathrm{mol}^{-1}$
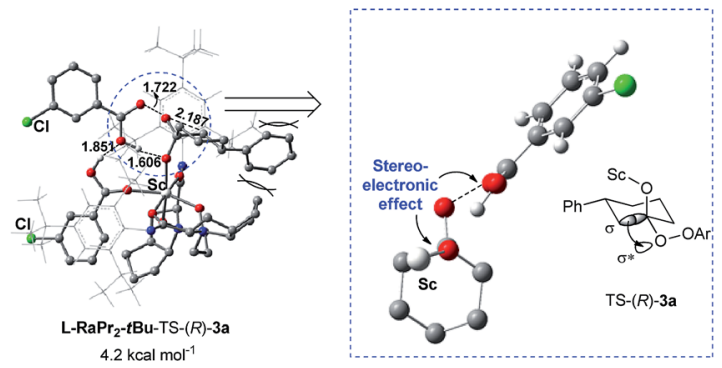

(c) Gibbs free energy of transition states in PKR via BV oxidation
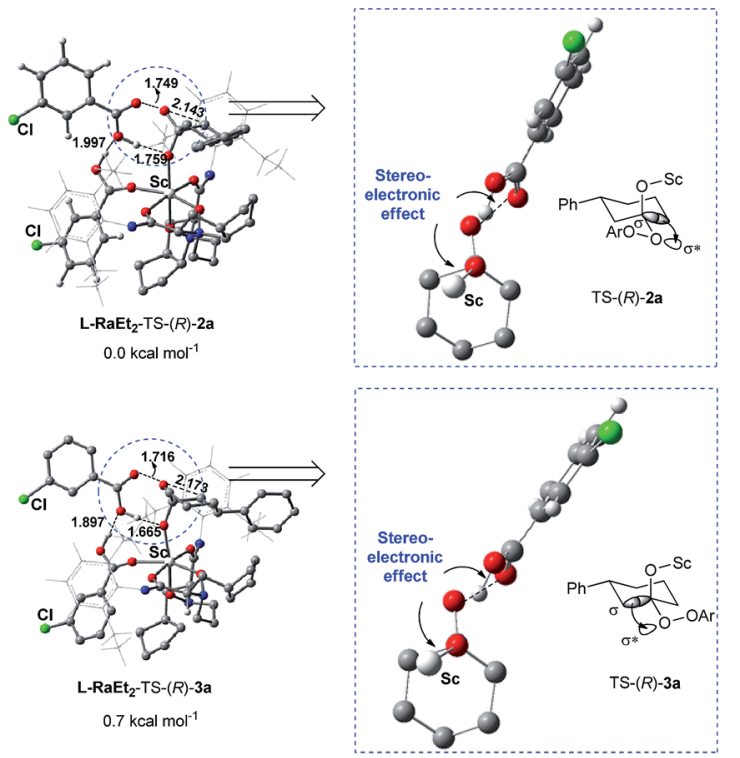

Fig. 2 Gibbs free energy diagram of the optimized transition states of $( \pm)-1 \mathrm{a}$ and $m$-CPBA catalyzed by $N, N^{\prime}$-dioxide/Sc(III) complexes.

backbone of the ligand. For $\mathbf{L}-\mathbf{R a P r}_{2}-\mathbf{t B u}$ with bulky iso-propyl and tert-butyl groups on the aniline group, the larger steric hindrance between the ligand and 1a resulted in a larger energy difference between L-RaPr $\mathbf{r}_{\mathbf{2}}-\mathbf{t} \mathbf{B u}-\mathrm{TS}-(R)-\mathbf{3 a}$ and $\mathbf{L}-\mathbf{R a P r}_{\mathbf{2}}-\mathbf{t B u}$-TS$(R)$-2a (Fig. $2 \mathrm{~b}, \Delta \mathrm{G}=4.2 \mathrm{kcal} \mathrm{mol}^{-1}$ ), and so the former is the favored transition state while the latter is the disfavored one. Meanwhile, owing to a less bulky aniline group and the flexible catalyst structure, the energy difference between $\mathbf{L}-\mathbf{R a E t}_{\mathbf{2}}$-TS- $(R)$ 3a and L-RaEt $\mathbf{2}_{\mathbf{2}}$-TS- $(R)$-2a was significantly smaller (Fig. $2 \mathrm{c}, \Delta \mathrm{G}=$ $0.7 \mathrm{kcal} \mathrm{mol}^{-1}$ ), and both transition states are favored. Such a revelation is consistent with the control experiments in Scheme 3. The theoretical study shows that the adjustable aniline groups and flexible catalyst structure proved to be powerful for the regioselectivity and enantioselectivity in the BV oxidation of 1 a with $N, N^{\prime}$-dioxide/Sc(III) catalysts through the recognition of the 3-position of the cyclohexanones in $\mathrm{BV}$ oxidation.

\section{Conclusions}

We realized the catalytic asymmetric CKR and PKR of 3substituted cyclohexanones and desymmetrization of mesodisubstituted cycloketones through BV oxidation with a single catalytic system. The pending problem of regio- and stereoselectivity in BV oxidation was solved by the modulation of the structure of chiral $N, N^{\prime}$-dioxide/Sc(III) complexes. The experimental studies and theoretical calculations showed that flexible and adjustable catalysts can influence the migratory aptitude of the substrate via stereoelectronic control and chiral recognition. Besides, this methodology has been proven to be efficient in synthesizing useful bioactive compounds and natural products.

\section{Conflicts of interest}

There are no conflicts to declare.

\section{Acknowledgements}

We acknowledge the National Natural Science Foundation of China (No. 21890723 and 21625205) and the Fundamental Research Funds for the Central Universities (2012017yjsy001) for the financial support.

\section{Notes and references}

1 A. Baeyer and V. Villiger, Ber. Dtsch. Chem. Ges., 1899, 32, 3625 .

2 For selected reviews, see: (a) G. R. Krow, Org. React., 1993, 43, 251; (b) G. Strukul, Angew. Chem., Int. Ed., 1998, 37, 1198; (c) M. Renz and B. Meunier, Eur. J. Org. Chem., 1999, 737; (d) G.-J. ten Brink, I. W. C. E. Arends and R. A. Sheldon, Chem. Rev., 2004, 104, 4105.

3 (a) C. Bolm, in Advances in Catalytic Processes, ed.M. P. Doyle, JAI Press, Greenwich, CT, 1997, vol. 2, p. 43; (b) C. Bolm and O. Beckmann, in Comprehensive Asymmetric Catalysis, ed. E. N. Jacobsen, A. Pfaltz and H. Yamamoto, Springer, Berlin, 1999, vol. 2, p. 803; (c) C. Bolm, Baeyer-Villiger Reaction, in Asymmetric Synthesis: The Essentials, ed. M. Christmann and S. Bräse, Wiley-VCH, Weinheim, Germany, 2006, p. 57; (d) L. Zhou, L. L. Lin, X. H. Liu and X. M. Feng, Baeyer-Villiger (BV) Oxidation/Rearrangement 
in Organic Synthesis, in Molecular Rearrangements in Organic Synthesis, ed. C. M. Rojas, Wiley-VCH, Weinheim, Germany, 2015, p. 35; (e) C. M. Crudden, A. C. Chen and L. A. Calhoun, Angew. Chem., Int. Ed., 2000, 39, 2851.

4 For selected examples of the asymmetric CKR of racemic cycloketones via BV oxidation, see: (a) C. Bolm, G. Schlingloff and K. Weickhardt, Angew. Chem., Int. Ed., 1994, 33, 1848; (b) A. Gusso, C. Baccin, F. Pinna and G. Strukul, Organometallics, 1994, 13, 3442; (c) Y. G. Peng, X. M. Feng, K. B. Yu, Z. Li, Y. Z. Jiang and C.-H. Yeung, J. Organomet. Chem., 2001, 619, 204; (d) M. T. Reetz and S. Wu, J. Am. Chem. Soc., 2009, 131, 15424; (e) L. Zhou, X. H. Liu, J. Ji, Y. H. Zhang, W. B. Wu, Y. B. Liu, L. L. Lin and X. M. Feng, Org. Lett., 2014, 16, 3938; $(f)$ N. C. Abascal and S. J. Miller, Org. Lett., 2016, 18, 4646.

5 For selected examples of the asymmetric PKR of racemic cycloketones via BV oxidation, see: (a) V. Alphand and R. Furstoss, J. Org. Chem., 1992, 57, 1306; (b) C. Bolm and G. Schlingloff, J. Chem. Soc., Chem. Commun., 1995, 1247; (c) A. Watanabe, T. Uchida, R. Irie and T. Katsuki, Proc. Natl. Acad. Sci. U. S. A., 2004, 101, 5737; (d) F. Hollmann, A. Taglieber, F. Schulz and M. T. Reetz, Angew. Chem., Int. Ed., 2007, 46, 2903; (e) S. Xu, Z. Wang, X. Zhang and K. Ding, Eur. J. Org. Chem., 2011, 110.

6 For selected examples of the desymmetrization of cyclobutanones via BV oxidation, see: (a) C. Bolm, T. K. K. Luong and G. Schlingloff, Synlett, 1997, 1151; (b) C. Paneghetti, R. Gavagnin, F. Pinna and G. Strukul, Organometallics, 1999, 18, 5057; (c) T. Uchida and T. Katsuki, Tetrahedron Lett., 2001, 42, 6911; (d) S.-I. Murahashi, S. Ono and Y. Imada, Angew. Chem., Int. Ed., 2002, 41, 2366; (e) S. Xu, Z. Wang, X. Zhang, X. Zhang and K. Ding, Angew. Chem., Int. Ed., 2008, 47, 2840; (f) L. Zhou, X. H. Liu, J. Ji, Y. H. Zhang, X. L. Hu, L. L. Lin and X. M. Feng, J. Am. Chem. Soc., 2012, 134, 17023.

7 For selected examples of the desymmetrization of cyclohexanones via BV oxidation, see: (a) M. J. Taschner and D. J. Black, J. Am. Chem. Soc., 1988, 110, 6892; (b) J. D. Stewart, K. W. Reed, C. A. Martinez, J. Zhu, G. Chen and M. M. Kayser, J. Am. Chem. Soc., 1998, 120, 3541; (c) M. T. Reetz, B. Brunner, T. Schneider, F. Schulz, C. M. Clouthier and M. M. Kayser, Angew. Chem., Int. Ed., 2004, 43, 4075; (d) D. V. Rial, D. A. Bianchi, P. Kapitanova, A. Lengar, J. B. van Beilen and M. D. Mihovilovic, Eur. J. Org. Chem., 2008, 1203; (e) A. Cavarzan, G. Bianchini, P. Sgarbossa, L. Lefort, S. Gladiali, A. Scarso and G. Strukul, Chem.-Eur. J., 2009, 15, 7930; (f) G. Li, M. J. L. J. Fürst, H. R. Mansouri, A. K. Ressmann, A. Ilie,
F. Rudroff, M. D. Mihovilovic, M. W. Fraaije and M. T. Reetz, Org. Biomol. Chem., 2017, 15, 9824.

8 (a) B. M. Trost, P. Buhlmayer and M. Mao, Tetrahedron Lett., 1982, 23, 1443; (b) V. Alphand, A. Archelas and R. Furstoss, Tetrahedron Lett., 1989, 30, 3663; (c) V. Alphand and R. Furstoss, Tetrahedron: Asymmetry, 1992, 3, 379.

9 (a) M. M. Kayser, G. Chen and J. D. Stewart, J. Org. Chem., 1998, 63, 7103; (b) S. Wang, M. M. Kayser and V. Jurkauskas, J. Org. Chem., 2003, 68, 6222; (c) H. Iwaki, S. Wang, S. Grosse, H. Bergeron, A. Nagahashi, J. Lertvorachon, J. Yang, Y. Konishi, Y. Hasegawa and P. C. K. Lau, Appl. Environ. Microbiol., 2006, 72, 2707; (d) M. J. Fink, T. C. Fischer, F. Rudroff, H. Dudek, M. W. Fraaije and M. D. Mihovilovic, J. Mol. Catal. B: Enzym., 2011, 73, 9; (e) T. Reignier, V. de Berardinis, J.-L. Petit, A. Mariage, K. Hamzé, K. Duquesnea and V. Alphand, Chem. Commun., 2014, 50, 7793; $(f)$ D. K. Romney, S. M. Colvin and S. J. Miller, J. Am. Chem. Soc., 2014, 136, 14019.

10 G. Ottolina, G. Carrea, S. Colonna and A. Rückemann, Tetrahedron: Asymmetry, 1996, 7, 1123.

11 (a) X. H. Liu, L. L. Lin and X. M. Feng, Acc. Chem. Res., 2011, 44, 574; (b) X. H. Liu, L. L. Lin and X. M. Feng, Org. Chem. Front., 2014, 1, 298; (c) X. H. Liu, H. F. Zheng, Y. Xia, L. L. Lin and X. M. Feng, Acc. Chem. Res., 2017, 50, 2621; (d) X. H. Liu, S. X. Dong, L. L. Lin and X. M. Feng, Chin. J. Chem., 2018, 36, 791; (e) J. Wang, Y. Zuo, C. Hu and Z. Su, Catal. Sci. Technol., 2017, 7, 2183.

12 (a) 5a (CCDC 1848335).†; (b) CCDC 1856535 (L-RaPr2-tBu/ $\mathrm{Sc}(\mathrm{OTf}) 3) \cdot \dagger$

13 A. T. Negmeldin, J. R. Knoff and M. K. H. Pflum, Eur. J. Med. Chem., 2018, 143, 1790.

14 (a) B. ter Horst, J. van Wermeskerken, B. L. Feringa and A. J. Minnaard, Eur. J. Org. Chem., 2010, 38; (b) Y. Huang, A. J. Minnaard and B. L. Feringa, Org. Biomol. Chem., 2012, 10, 29; (c) S. Chow, M. T. Fletcher, L. K. Lambert, O. P. Gallagher, C. J. Moore, B. W. Cribb, P. G. Allsopp and W. Kitching, J. Org. Chem., 2005, 70, 1808; (d) B. ter Horst, B. L. Feringa and A. J. Minnaard, Org. Lett., 2007, 9, 3013; (e) Y. Zhu, A. Loudet and K. Burgess, Org. Lett., 2010, 12, 4392; (f) K. Matcha, A. V. R. Madduri, S. Roy, S. Ziegler, H. Waldmann, A. K. H. Hirsch and A. J. Minnaard, ChemBioChem, 2012, 13, 2537; $(g)$ D. Geerdink, J. Buter, T. A. van Beek and A. J. Minnaard, Beilstein J. Org. Chem., 2014, 10, 761; (h) J.-H. Tay, A. J. Argüelles, M. D. DeMars II, P. M. Zimmerman, D. H. Sherman and P. Nagorny, J. Am. Chem. Soc., 2017, 139, 8570.

15 N. Yang, Z. S. Su, X. M. Feng and C. W. Hu, Chem.-Eur. J., 2015, 21, 7264 . 